\title{
Evidence-based guideline for neuropathic pain interventional treatments: Spinal cord stimulation, intravenous infusions, epidural injections and nerve blocks
}

\author{
Angela Mailis MD MSc FRCPC(PhysMed), Paul Taenzer PhD RPsych
}

\begin{abstract}
A Mailis, P Taenzer. Evidence-based guideline for neuropathic pain interventional treatments: Spinal cord stimulation, intravenous infusions, epidural injections and nerve blocks. Pain Res Manage 2012;17(3):150-158.
\end{abstract}

BACKGROUND: The Special Interest Group of the Canadian Pain Society has produced consensus-based guidelines for the pharmacological management of neuropathic pain. The society aimed to generate an additional guideline for other forms of neuropathic pain treatments.

OBJECTIVE: To develop evidence-based recommendations for neuropathic pain interventional treatments.

METHODS: A task force was created and engaged the Institute of Health Economics in Edmonton, Alberta, to survey the literature pertaining to multiple treatments. Sufficient literature existed on four interventions only: spinal cord stimulation; epidural injections; intravenous infusions; and nerve blocks. A comprehensive search was conducted for systematic reviews, randomized controlled trials and evidence-based clinical practice guidelines; a critical review was generated on each topic. A modified United States Preventive Services Task Force tool was used for quality rating and grading of recommendations.

RESULTS: Investigators reviewed four studies of spinal cord stimulation, 19 studies of intravenous infusions, 14 studies of epidural injections and 16 studies of nerve blocks that met the inclusion criteria. The task force chairs rated the quality of evidence and graded the recommendations. Feedback was solicited from the members of the task force.

CONCLUSION: There is sufficient evidence to support recommendations for some of these interventions for selected neuropathic pain conditions. This evidence is, at best, moderate and is often limited or conflicting. Pain practitioners are encouraged to explore evidence-based treatment options before considering unproven treatments. Full disclosure of risks and benefits of the available options is necessary for shared decision making and informed consent.

Key Words: Clinical practice guideline; Evidence-based; Interventions; Neuropathic pain

Chronic neuropathic pain is caused by lesions or dysfunction of the peripheral or central nervous system. Despite a significant increase in the number of randomized controlled trials (RCTs) in neuropathic pain over the past few years, fewer than one-half of the patients appear to achieve satisfactory relief with pharmacological agents $(1,2)$. To guide clinical practice, several societies and organizations have produced guidelines evaluating the effectiveness of pharmacological treatments for neuropathic pain $(3,4)$. Additionally, there is a plethora of guidelines assessing interventional treatments for various forms of chronic pain (5-13).

The Canadian Pain Society Special Interest Group on Neuropathic Pain (NePSIG) produced a consensus clinical practice guideline (CPG) on pharmacological treatments for neuropathic pain (4) and was interested in generating an additional guideline addressing the evidence on interventional treatments for this very complex type of pain. The purpose of the present guideline is to present evidence-based recommendations for the use of invasive procedures in the management of neuropathic pain.

\begin{abstract}
Des lignes directrices probantes à l'égard des traitements interventionnistes pour soigner les douleurs neuropathiques : la stimulation de la moelle épinière, les infusions intraveineuses, les injections péridurales et les anesthésies tronculaires
\end{abstract}

\begin{abstract}
OBJECTIF : Élaborer des recommandations probantes à l'égard des traitements interventionnistes de la douleur neuropathique.

HISTORIQUE : Le groupe d'intérêt spécial de la Société canadienne pour le traitement de la douleur a produit des lignes directrices consensuelles sur la prise en charge pharmacologique de la douleur neuropathique. La Société avait l'intention de produire d'autres lignes directrices sur les autres formes de traitement de la douleur neuropathique.

MÉTHODOLOGIE : Un groupe de travail a été mis sur pied et a retenu les services de l'Institut d'économie de la santé d'Edmonton, en Alberta, pour parcourir les publications au sujet de multiples traitements. Seulement quatre traitements s'associaient à un assez grand nombre de publications : la stimulation de la moelle épinière, les injections péridurales, les infusions intraveineuses et les anesthésies tronculaires. On a entrepris une recherche approfondie afin de trouver des analyses systématiques, des essais aléatoires et contrôlés et des guides de pratique clinique probants et produit une analyse critique sur chaque traitement. On a utilisé un outil modifié du groupe de travail sur les services préventifs des États-Unis pour évaluer la qualité et les catégories de recommandations. RÉSULTATS : Les chercheurs ont examiné quatre études sur la stimulation de la moelle épinière, 19 études sur l'infusion intraveineuse, 14 études sur les injections péridurales et 16 études sur les anesthésies tronculaires qui respectaient les critères d'inclusion. Les présidents des groupes de travail ont évalué la qualité des données probantes, classé les recommandations et sollicité les commentaires des membres.

CONCLUSION : Les données probantes sont suffisantes pour appuyer les recommandations relatives à certaines de ces interventions à l'égard de troubles de douleur neuropathique précis. Au mieux, les données probantes sont modérées et sont souvent limitées ou conflictuelles. Les praticiens de la douleur sont invités à explorer les possibilités de traitement probantes avant d'envisager des traitements dont l'efficacité n'est pas démontrée. Il faut divulguer tous les risques et les avantages des possibilités offertes pour parvenir à une prise de décision partagée et à un consentement éclairé.
\end{abstract}

Preface/panel composition

\section{METHODS}

In the spring of 2007, the NePSIG invited the authors to serve as cochairs of a task force for the creation of evidence-based guidelines on neuropathic pain treatments other than oral pharmacotherapies.

\begin{abstract}
Target audience and scope
The target audience for the present guideline is physicians and health care teams involved in the diagnosis and management of neuropathic pain. The target population is adults with neuropathic pain of various etiologies.
\end{abstract}

\section{Evidence review}

To help prioritize the list of interventions to be reviewed, a Canadian Pain Society (CPS) survey solicited members' views on which treatments, other than oral medications, are most important for neuropathic pain. In rank order, the members asked for guidance on the following topics: cognitive behavioural treatments; nerve blocks;

${ }^{1}$ Department of Medicine, University of Toronto, Toronto Western Hospital, Toronto, Ontario; ${ }^{2}$ Departments of Psychiatry, Medicine and

Oncology, University of Calgary, Calgary, Alberta

Correspondence: Dr Angela Mailis, Department of Medicine, University of Toronto, Toronto Western Hospital, 4F811, 399 Bathurst Street,

Toronto, Ontario M5T 2S8. Telephone 416-603-5380, fax 416-603-5725, e-mail angela.mailis@uhn.on.ca 
acupuncture; transcutaneous electrical nerve stimulation; intravenous (IV) infusions; spinal cord stimulation; nerve blocks; and epidural injections.

The CPS engaged the Health Technology Assessment (HTA) Unit of the Institute of Health Economics in Edmonton, Alberta (14), to conduct a preliminary literature search and appraisal of the available research on the above topics. Given time and resource constraints, a predefined methodology was agreed on between the authors and HTA researchers that the literature review will include systematic reviews (SRs), RCTs and evidence-based CPGs on each proposed intervention. The preliminary search revealed that the literature that focused on treatment of patients with neuropathic pain existed only for the following four topics: IV infusions; spinal cord stimulators (SCS); nerve blocks and epidural injections. The HTA researchers were subsequently instructed to gather and rate the quality of the available scientific literature on these four interventions.

The HTA researchers generated four reports and three addendums providing a summary and critical appraisal of the available published evidence from the international medical literature pertaining to the use of epidural injections, nerve blocks, IV infusions and SCS for the treatment of neuropathic pain.

\section{Inclusion criteria}

The studies included were SRs, RCTs published after the end date of the search strategy of the included SRs, and CPGs. The selection criteria, literature search strategy, selection, appraisal of retrieved studies, and outcome measures and data extraction followed a rigorous process.

\section{SRs}

An article was deemed to be an SR if it met all of the following criteria as defined by Cook et al (15): focused clinical question; explicit search strategy; use of explicit, reproducible and uniformly applied criteria for article selection; critical appraisal of the included studies; and qualitative or quantitative data synthesis.

\section{RCTs and quasi-RCTs}

RCTs and trials using a quasi-random method of treatment allocation (quasi-RCTs), such as date of birth, day of the week or medical record number, were included.

\section{CPGs}

CPGs are most commonly defined as "systematically developed statements to assist practitioner and patient decisions about appropriate health care for specific clinical circumstances" (16). For a CPG to be valid, the evidence supporting its recommendations must be cited $(16,17)$. Therefore, an article was deemed to be a CPG if it met all of the following criteria: contained the word 'guideline' or 'recommendation' in its title or introduction, or contained recommendations on managing patients with neuropathic pain in the form of advice or instructions (18); was developed by at least two authors; and was evidence based.

CPGs that were not evidence based, such as consensus statements that contained recommendations based only on expert opinion, were excluded. Only CPGs formulated in countries with developed market economies were included because the health status, cultural norms, access to health care and disease burden of individuals from countries with transitional or developing economies were likely to be too different from those of Canada to be clinically relevant. Countries or regions deemed to have developed economies, as defined by the United Nations, were as follows: Australia, Canada, Japan, New Zealand, the United States (US) and Europe (except for Albania, Bulgaria, Czech Republic, Hungary, Poland, Romania, Slovakia, Bosnia and Herzegovina, Croatia, Slovenia, the former Yugoslav Republic of Macedonia, Yugoslavia, Estonia, Latvia, Lithuania, Belarus, the Republic of Moldova, the Russian Federation and Ukraine) (19).

\section{Participants}

Data regarding adult patients with a peripheral or central neuropathic pain condition of any duration were collected. Studies that referred to 'patients' or 'adult patients' without providing a specific age range were also included. However, any study that clearly included patients younger than 18 years of age was excluded (except for CPGs in which the age restriction was removed to increase the number of CPGs suitable for the present review). Patients with cancer pain were excluded unless they had a defined postsurgical pain syndrome with neuropathic contribution such as postmastectomy pain. Patients with visceral pain, migraine, headache, fibromyalgia or ischemic pain were excluded.

\section{Index interventions}

- Any type of implantable SCS.

- Epidural injection of any drug via a caudal, interlaminar or transforaminal approach for treating neuropathic pain. Diagnostic epidural injections were not included.

- Therapeutic IV infusions of any drug for treating neuropathic pain. Diagnostic IV infusions and IV sympathetic blocks were not included.

- Peripheral nerve blocks, sympathetic nerve blocks, regional nerve blocks and paravertebral or trigger point blocks using any drug for the treatment of neuropathic pain. Diagnostic nerve blocks were not included.

\section{Comparative intervention}

Any medical, mechanical or surgical intervention designed to treat patients with neuropathic pain. Placebo and no treatment comparisons were also included. Studies that compared technical aspects or different modalities of spinal cord stimulation were excluded.

\section{Literature search strategy}

The medical literature was searched to identify relevant, publicly available SRs, RCTs and CPGs published in English from January 1997 to May 2008 (Appendix A in each of references 20 to 23). Although the bibliographies of articles retrieved in hard-copy form were not systematically searched for relevant references that may have been missed in the database searches (pearling), any additional relevant references uncovered during the examination of these full-text articles were retrieved.

\section{Literature selection process}

Study selection was conducted by one reviewer. Articles that clearly did not meet the inclusion criteria based on their abstract were excluded. Copies of the full text of potentially eligible studies were retrieved. In some cases, when the full text of the article was retrieved, closer examination revealed that it did not meet the inclusion criteria. Consequently, these articles were excluded (Appendix B in each of references 20 to 23 ).

\section{SRs}

In cases where multiple SRs on a single topic were identified that were of the same quality and had identical comparators and patient populations, only the most recently published SR was included. In cases where an SR described a particular subgroup of neuropathic pain patients (eg, postherpetic neuralgia [PHN], radiculopathy) or used different or additional comparators from those of the most recent SR, both SRs were included.

\section{RCTs and quasi-RCTs}

RCTs or quasi-RCTs that covered the same interventions and patient groups detailed in the included SRs and were published after the end date of the search strategy of the included SRs were also included. When overlapping patient groups were reported in RCTs, only the article(s) quoting the most complete data set was used.

\section{CPGs}

In cases where multiple CPGs on a single topic that were of the same quality and had identical comparators and patient populations were 
identified, only the most recently published CPG was included. In cases where a CPG described a particular subgroup of neuropathic pain patients (eg, PHN, radiculopathy) or used additional or different comparators from those of the most recent $\mathrm{CPG}$, both CPGs were included.

In cases where multiple CPGs on a single topic that had identical comparators but were of differing quality were identified, only the highest quality CPG was included if it was also the most recent. If the highest quality CPG was not the most recent, then both the highest quality CPG and the most current CPG, regardless of quality, were included.

\section{Assessment methods}

Study methodology appraisal: The included studies were assessed with respect to various aspects of methodology and reporting using checklists specific for each particular study type (Appendixes C, D and $E$ in each of references 20 to 23 ). The quality assessments were undertaken independently by two reviewers. The checklists were operationalized by constructing dictionaries that explained each criterion. The two reviewers discussed the dictionaries with respect to the interpretation of questions before assessing the studies. Critical appraisal results for all included studies are tabulated in Appendixes C, D and E in each of references 20 to 23. Details of the assessment process for all evidence are presented in the Appendix of the present guideline.

Outcome measures and data extraction: Study profile information, in addition to relevant safety and efficacy data, were extracted by one reviewer using standardized data extraction forms developed a priori.

\section{Grading of the evidence and recommendations}

The co-chairs of the task force tabulated the HTA reports by accepting only results of good/moderate-quality RCTs, and evidence-based SRs and CPGs of average and good quality.

To grade the strength of recommendations, the co-chairs chose the US Preventive Services Task Force (USPSTF) grading system (2008 version) because it contains a quality rating of evidence used as well as grading of evidence (24). The USPSTF tool was modified by adding evidence-based CPGs as an evidence source (25). All outcomes (positive and negative) were tabulated and analyzed qualitatively to classify the recommendations in four categories: those supported by strong evidence; those supported by some evidence; recommendation against; and no recommendation because there was not enough evidence for or against. Recommendations from source documents that were markedly different for the same intervention were considered to be conflicting. For interventions recommended by several sources of evidence, the authors of the present guideline erred on the side of caution (for example, if a particular intervention carried moderate evidence for three sources and strong evidence from one, the final recommendation in the present document would indicate that the level of evidence was moderate).

The USPSTF tool includes three elements:

1. Quality of evidence used.

- Good: Results must be consistent; the studies are well designed; the populations are representative.

- Fair: There is evidence of benefit but strength of evidence is limited by number, quality or consistency of studies included, or generalizability.

- Poor: Evidence is insufficient to assess effects on health outcomes because of limited number or power of studies, important flaws in design or conduct, etc.

2. Certainty with regard to quality of evidence.

- High: The evidence includes consistent results from good-quality studies representative of the population in question. The conclusion, therefore, is unlikely to be affected or changed by the results of future studies.

- Moderate: While the available evidence is sufficient to determine the effects on health outcomes; confidence in the estimate is constrained by the number, size or quality of studies, inconsistency of findings, limited generalizability or lack of coherence in chain of evidence. Further studies may change the conclusion.

- Low: Available evidence is insufficient to assess effect because of limited number or power of studies, important flaws in design or conduct, etc.

3. Grade of recommendations

- A: Recommend. High certainty with substantial net benefit.

- B: Recommend. High certainty with moderate effect or moderate certainty with moderate to substantial effect.

- C: May recommend depending on circumstances. At least moderate certainty with small net benefit.

- D: Recommend against. Moderate or high certainty that there is no net benefit or that harm outweighs benefit.

- I: Current evidence is insufficient to make a recommendation for or against using the intervention (poor quality of evidence, conflicting evidence, or benefits and harms cannot be determined).

\section{Guideline development process}

The co-chairs of the task force met several times with the HTA group, in person and via teleconferences between April 2008 and April 2009, to develop the scope and key questions to guide the evidence review and to examine and discuss the results of the evidence review. The chairs drafted preliminary recommendations for each reviewed intervention and circulated them to the members of NePSIG who had declared an interest in participating in the guideline development process. They also presented progress reports to the NePSIG general assembly during the annual CPS meeting in 2009 and 2010. Additionally, a face-to-face meeting with the CPS interventional special interst group was arranged in May 2010 to clarify differences between the available evidence and members' expert opinion.

\section{RESULTS}

The four reports and three addendums generated by the HTA group comprise summaries and appraisals of the literature on SCS, IV infusions, epidural injections and nerve blocks for neuropathic pain, and are available for download from the CPS website (20-23, addendums 26-28).

The following narrative recommendations are based on this evidence.

\section{Recommendations for SCS}

The HTA retrieved four studies, two RCTs $(29,30)$, one SR (31) and one CPG (32). The SR (31) was of poor quality and excluded from the evidence. One RCT (30) and the CPG (32) supported the use of SCS. Kemler et al (29) concluded that SCS does not produce durable and statistically significant improvement in pain. However, at five years follow-up in this RCT, $35 \%$ of SCS patients versus $15 \%$ of the comparator reported statistically significant improved global effect, and that 19 of 20 SCS patients would undergo the procedure again. This was considered by the task force chairs as clinically relevant and was taken into consideration when formulating the recommendation.

Failed back surgery syndrome and complex regional pain syndrome: In patients with failed back surgery syndrome and complex regional pain syndrome (CRPS I or II), who are not candidates for corrective surgery and have failed more conservative evidence-based treatment, clinicians should consider offering a trial of SCS.

Evidence quality: Good; Certainty: Moderate; Strength of recommendation: Grade B

Traumatic neuropathy and brachial plexopathy: In patients with traumatic neuropathy and brachial plexopathy, who are not candidates for corrective surgery and who have failed more conservative evidencebased treatment, clinicians may consider offering a trial of SCS.

Evidence quality: Fair; Certainty: Moderate; Strength of recommendation: Grade C 
Other neuropathic pain syndromes: In patients with other (than the above) neuropathic pain syndromes, there is insufficient evidence to recommend a trial of SCS.

Evidence quality: Poor; Certainty: Low; Strength of recommendation: Grade I.

\section{Recommendations for IV infusions}

The HTA retrieved five SRs (33-37), 11 RCTs (38-48) and one CPG (12). Two SRs $(36,37)$ were considered to be of poor quality and excluded, while the CPG (12) reporting on lipoprostaglandin E1 was also excluded because the agent used was considered to be experimental. Only one trial existed on IV magnesium versus saline in PHN (39) and was considered inadequate evidence to furnish any recommendation. The reviewed studies reported on a multiplicity of IV infusions and for different neuropathic conditions (CRPS, PHN, peripheral nerve injury, painful diabetic neuropathy, phantom limb pain, spinal cord injury, lumbar radicular pain and spinal stenosis).

IV lidocaine: In patients with neuropathic pain, who have not derived sufficient benefit from pharmacological treatment, clinicians may consider a trial of IV lidocaine at doses of $5 \mathrm{mg} / \mathrm{kg}$ to $7.5 \mathrm{mg} / \mathrm{kg}$ body weight for pain relief lasting from a few hours to four weeks.

Evidence quality: Good; Certainty: Moderate; Strength of recommendation: Grade B

Some patients with treatment-resistant neuropathic pain may experience pain relief for up to several weeks. However, the response to IV lidocaine does not predict long-term response to its oral counterpart, mexiletine. Furthermore, there is no literature pertaining to the effectiveness of repeated IV lidocaine infusions.

IV biphosphonates: For patients with CRPS, who have not responded adequately to less invasive options, clinicians may consider a trial of IV biphosphonates, which may produce long term ( $>1$ month) benefit.

Evidence quality: Good; Certainty: Moderate; Strength of recommendation: Grade B

IV ketamine: While there is good quality evidence to support the use of IV ketamine for short-term benefit ( $<1$ week) in some patients with neuropathic pain, the risk for adverse effects is high. Therefore, given this risk versus benefit picture, the present task force recommends that IV ketamine is not a clinically viable treatment option for these patients unless performed in hospital settings under a specialist's care. Evidence quality: Good; Certainty: Moderate; Strength of recommendation: Grade B

In patients with neuropathic pain, there is insufficient evidence to recommend IV ketamine as a long-term treatment strategy.

\section{Recommendations for epidural injections}

The HTA retrieved three SRs $(33,49,50)$, five RCTs $(51-55)$ and six CPGs (7-12,) for epidural injections of all types for neuropathic pain. One SR (50) and one CPG (11) were excluded due to poor quality. The vast majority of the reviewed studies related to lumbar epidural injections for radicular pain and/or failed back surgery syndrome, and several focused on spinal stenosis. The current recommendations arise from the following studies: one SR (49); five RCTs (51-55); and three CPGs $(8,9,12)$. Only three studies included information on cervical epidurals: one SR (49), one RCT (54) and one CPG (8). For lumbar injections for lumbar radicular pain, four RCTs are included in the present guideline that compared route of epidural administration (51), and one type of epidural injection with a noninvasive treatment option (52) or two types of epidural injectables or doses (53-55). While all of these studies demonstrated the positive effects of various epidural injections, only one RCT (51) provided evidence that the transforaminal approach was more effective than the other two epidural approaches. The following recommendations are derived from qualitative synthesis of the evidence-based CPGs and SRs included in the review.

Lumbar radiculopathy: In patients with lumbar radiculopathy, who did not adequately respond to conservative treatment, clinicians may consider a trial of lumbar epidural steroid injections.
Evidence quality: Fair; Certainty: Moderate; Strength of recommendation: Grade B (short term relief up to three months)

Evidence quality: Fair; Certainty: Moderate; Strength of recommendation: Grade C (long-term relief of up to one year)

When there is no substantial clinical benefit, it is difficult to justify more than two to three caudal or transforaminal epidural steroid injections for this condition. There is no evidence, however, to support that multiple injections will generate long-term relief.

In particular, research evidence obtained from the reviewed studies listed above (one SR [49] and three CPGs [8,9,12]) provide some support for the use of epidural steroid injections for up to 12 weeks of relief from pain resulting from chronic lumbar radiculopathy (interlaminar, transforaminal and caudal), but the evidence reported varies between moderate and strong. The same sources provide an even more confusing report on evidence that ranged between conflicting to moderate, for the use of different types of epidural injections involving steroids with or without local anesthetic, for long-term (up to one year) relief of pain due to chronic lumbar radiculopathy. Only the New Zealand Accident Compensation CPG (8) commented on use of repeat epidurals and suggested that when there is no substantial clinical benefit, it is difficult to justify more than two to three caudal or transforaminal epidural steroid injections without specifying time frame. However, this CPG made no mention of the number of injections in case there is some effectiveness, while another CPG (12) recommended "multiple guided" epidurals for long-term relief.

Cervical radiculopathy and brachialgia: In patients with neuropathic pain arising from the cervical spine/roots, the use of cervical epidural injections should only be considered in exceptional circumstances when adequate trials of conservative and less-invasive treatment have failed to provide adequate benefit.

Evidence quality: Fair; Certainty: Moderate; Strength of recommendation: Grade C

Research evidence provides some support for the use of cervical epidural steroid injections for relief up to eight to 12 weeks, and occasionally, up to one year for pain resulting from chronic cervical radiculopathy and brachialgia. However, cervical epidural injections are associated with rare but occasionally catastrophic adverse events including quadriplegia and death, especially in untrained hands. Only skilled practitioners with extensive experience should perform these blocks.

Spinal stenosis: There is insufficient evidence to evaluate short-term effectiveness, and conflicting evidence for long-term effectiveness of various types of epidural injections for spinal stenosis.

Evidence quality: Fair; Certainty: Low; Strength of recommendation: Grade I

Failed back surgery syndrome: There is limited/conflicting evidence supporting the short-term effectiveness of caudal and transforminal epidurals in patients with failed back surgery syndrome.

Evidence quality: Fair; Certainty: Low; Strength of recommendation: Grade I

CRPS I: There is insufficient evidence to evaluate effectiveness of epidural clonidine or epidural steroid/anesthetic injections in the treatment of CRPS I.

Evidence quality: Fair; Certainty: Low; Strength of recommendation: Grade I

PHN: There is insufficient evidence to evaluate effectiveness of epidural steroid/anesthetic injections in the treatment of PHN.

Evidence quality: Fair; Certainty: Low; Strength of recommendation: Grade I

\section{Recommendations for nerve blocks}

The HTA retrieved four SRs $(33,50,56,57)$, six RCTs $(58-63)$ and six CPGs $(7,8,10,11,64,65)$. One SR $(50)$ and three CPGs $(11,64,65)$ were excluded due to poor quality. The recommendations refer to commonly used blocks.

Nerve blocks for lumbar radiculopathy: Based on limited evidence that selective transforaminal nerve root blocks (extraforaminal root 
injections, periradicular steroid injections, intraforaminal oxygenozone injections and epidural perineural autologous conditioned serum injections can provide up to eight to 12 weeks of relief from lumbar radicular pain, the task force cannot justify a general recommendation, but suggests that these interventions be used with caution depending on the circumstances, with full disclosure to the patient of the limited evidence and potential risks.

Evidence quality: Fair; Certainty: Moderate; Strength of recommendation: Grade C

IV regional guanethidine and Bier blocks for CRPS I: IV regional guanethidine and Bier blocks are not recommended for the treatment of CRPS I.

Evidence quality: Good; Certainty: Moderate; Strength of recommendation: Grade D

Stellate ganglion blocks for PHN: Stellate ganglion blocks are not recommended for the treatment of PHN.

Evidence quality: Fair; Certainty: Moderate; Strength of recommendation: Grade D

Peroneal nerve blocks for lumbar radicular pain: Peroneal nerve blocks are not recommended for the treatment of lumbar radicular pain.

Evidence quality: Good; Certainty: Moderate; Strength of recommendation: Grade D

Selective nerve root blocks for cervical radiculopathy: There is insufficient evidence to evaluate effectiveness of selective nerve root blocks in cervical radicular pain.

Evidence quality: Fair; Certainty: Moderate; Strength of recommendation: Grade I

Stellate ganglion blocks for CRPS I: There is insufficient evidence to evaluate effectiveness of stellate ganglion blocks in CRPS I.

Evidence quality: Fair to Poor; Certainty: Moderate; Strength of recommendation: Grade I

\section{DISCUSSION}

Effective treatment for neuropathic pain is often elusive (66-70). While a number of pharmacological agents have demonstrated efficacy, clinicians report that patients frequently experience inadequate relief after careful sequential trials of the evidence-based pharmacological options recommended in the available CPGs, including the guideline published by the CPS (4). For the present guideline, the NePSIG of the CPS has examined the evidence for treatment options other than oral pharmacological treatment. This process included input from the CPS membership on the scope of the guideline and from a panel of multidisciplinary experts who reviewed draft recommendations in light of the available evidence.

While members of the CPS indicated that cognitive behavioural therapy, acupuncture and transcutaneous electrical nerve stimulation were treatments of great interest to practicing clinicians, the existing literature on these approaches does not focus on their effectiveness for patients with neuropathic pain. As a result, evidence-based recommendations for these modalities in the treatment of neuropathic pain are not possible at this time.

However, evidence in the form of RCTs, SRs and published, evidencebased CPGs was found for SCS, IV infusions, nerve blocks and epidural steroids. This evidence proved to be limited. While several interventions are supported by good-quality evidence, limited numbers of trials and small sample sizes limit the recommendations to Grade B at best. Grade B recommendations include the use of SCS for failed back surgery syndrome and CRPS, and IV lidocaine, bisphophonates and ketamine for short-term pain relief. Due to inconsistency in the use of the terms 'short-term' and 'long-term' relief, time frames based on the primary research are specified in each recommendation. For the other interventions and neuropathic conditions the levels of evidence are lower (ie, C) generating even less certainty of benefit or conflicting/limited evidence, leading to inability to even furnish a recommendation. Additionally, for a number of interventions (stellate ganglion blocks for PHN, IV guanethidine and Bier blocks for CRPS and peroneal nerve blocks for lumbar radicular pain), the evidence leads to recommendation against the interventions, while for some interventions the existing evidence did not enable us to make any recommendations. Furthermore, a number of these interventions are associated with risks of adverse events, some of which are catastrophic.

While high-quality evidence is sparse in many areas of health care, including pain management, the problem is particularly salient in neuropathic pain. Patients with treatment-resistant neuropathic pain are desperate for help and their providers will do their utmost to provide relief. In the absence of evidence to guide clinical decision making, patients are more vulnerable to submitting to well-intended but unproven and potentially harmful interventions (71).

In circumstances where the evidence supporting specific treatment options is weak, benefits are likely to be modest and risks may be substantial. There is an important role for clinician-patient dialogue and shared decision making. The latter includes a careful review of the known risks, benefits, mitigating factors, and patient expectations and preferences $(72,73)$. The discussion should also include a frank disclosure of what evidence is lacking and how lack of evidence impacts the level of certainty of clinical decision making for the specific patient.

The present study has the following limitations. The literature reviewed consisted of SRs, RCTs published after the last included SR, and evidence-based CPGs, although the ultimate/ideal evidence-based guideline should include only good-quality RCTs. Additionally, the literature search terminated in May 2008, which excludes newer trials and other sources of evidence. More recent studies (not included in the present review) have further highlighted significant differences between guidelines and guideline processes with regard to certain interventions. For example, a guideline for interventions for low back pain with or without radiculopathy that was published after our own review was concluded (6), suggested a shared decision model with respect to epidural steroid injections for radicular pain (because the recommendation was considered to be weak and the evidence was of moderate quality). The authors also suggested that the short-term benefits are moderate and evidence for long-term benefits is lacking. To the contrary, another guideline generated by interventional physicians (5) presented significantly more positive recommendations for the same interventions. A "warfare over interventional therapies" for low back pain subsequently erupted (74). The 'jury is still out' for clinicians who seek guidance on interventions. This is illustrated by significant differences in the conclusions of recently published relevant studies, which were not part of our literature search. A very recent RCT on epidural steroids (75) indicated no long-term benefit when compared with placebo; an RCT of fluoroscopic caudal epidural injections for disc herniation and lumbar radiculopathy (76) indicated benefit, with steroids being superior to local anesthetics, while a metaanalysis on transforaminal injection of steroids for lumbar radiculopathy that searched the literature between 1966 and 2009 (77) concluded that these injections can result in improvement of pain, but not disability, and that adding steroids to a local anesthetic injection offers no advantage. In summary, no matter how one views the interventional literature, caution and a shared decision-making model are of paramount importance for practicing clinicians.

Even in the domains where Grade B evidence is available, many unanswered questions remain, underscoring the need for further highquality trials to clarify these many pivotal issues for this vulnerable patient population such as the following:

- Who is a candidate and who is at risk for adverse events?

- What are important technical considerations in the context of care, such as availability of imaging during a procedure, to minimize adverse events?

- What constitutes an adequate trial and what are the upper limits for repeat procedures?

- Where does the intervention fit in the overall context of care; is it an adequate 'solo treatment' or does it serve best as a facilitator in a comprehensive rehabilitation program? 
Individual clinicians do have the opportunity to contribute to the quality of their own clinical decision making in this area by systematically documenting the clinical benefits and adverse events in their own patients. Benefits of interest include pain relief, improved function and quality of life. These data can contribute a degree of precision and certainty in guiding individualized sequential treatment trials for all modalities of care including the interventions discussed in the present guideline.

\section{CONCLUSION}

Available data support some evidence-based recommendations for SCS, epidural injections, certain nerve blocks and IV injections for selected neuropathic pain conditions. However, the evidence for most interventions is weak/limited or insufficient. Many nonpharmacological treatment options currently in use for neuropathic pain, including many forms of interventional therapy, have not been investigated using high-quality clinical trial methods. The CPS NePSIG encourages practitioners to explore evidence-based treatment options before considering unproven treatments. Full and careful disclosure of the known and unknown risks and benefits of available options is necessary for shared decision making and truly informed consent.

\section{APPENDIX: ASSESSMENT OF EVIDENCE}

\section{SRs}

The included SRs were assessed using a checklist developed in-house that was adapted from a number of sources (20-23 [Appendix C]) (7881). This tool was chosen because it is more detailed and less subjective than other commonly used tools, such as the AMSTAR (82) and Oxman and Guyatt (83) checklists, and the reviewers were very experienced in its use. Any disagreements in scoring between the two reviewers that could not be resolved by discussion were referred to a third reviewer for mediation until consensus was reached. The quality of SRs was assessed according to how well their methods excluded bias and confounding by examining: the search strategy used; how the data extraction, quality assessment of the included studies, and data analysis/synthesis were conducted; and whether the conclusions of the review match the results. Thus, the quality of the SR was rated numerically with respect to six quality subsections (grey boxes in checklist) as follows:

Good: six criteria met, or five criteria met and one criterion 'unclear'. Average: one criterion not met, or one criterion not met and one criterion 'unclear', or two criteria 'unclear'.

Poor: at least two criteria not met.

\section{Randomized controlled trials}

The included RCTs were assessed using the criteria list recommended in the method guidelines of the Cochrane Back Review Group for SRs (Appendix D) (84).This list has been used in a number of systematic reviews (85-87) in the field of chronic pain and includes all the criteria from the lists generated by Jadad et al (88) and Verhagen et al (89). It consists of internal and external validity criteria, as well as statistical criteria. The list was modified by removing items $\mathrm{E}$ (Was the care provider blinded?) and $\mathrm{G}$ (Was compliance acceptable?), because blinding of the care provider is generally not possible in SCS and compliance is not a relevant issue when SCS is the sole treatment. In addition, some instructions were reworded or supplemented with more detailed criteria descriptions from Downs and Black (90). A simple nominal rating scale was used such that the studies were scored as positive (yes), negative (no), or unclear (don't know) for each quality criterion. Any disagreements in scoring between the two reviewers that could not be resolved by discussion were referred to a third reviewer for mediation until consensus was reached.

For descriptive purposes, the included RCTs were referred to as being good, moderate, or poor quality with respect to internal and external validity according to the total number of criteria met as follows:
- Internal validity (total number of criteria $=9)$ : $\operatorname{good}(\geq 7$ criteria met); moderate (between 4 and 6 criteria met); poor $(<4$ criteria met).

- External validity (total number of criteria $=6)$ : $\operatorname{good}(\geq 5$ criteria met); moderate ( 3 or 4 criteria met); poor ( $<3$ criteria met).

\section{CPGs}

The included CPGs were assessed using the Appraisal of Guidelines for Research and Evaluation (AGREE) instrument (91 [Appendix E]). The AGREE instrument is an internationally developed, generic tool that is validated, transparent and widely accepted, with satisfactory reliability for most domains. The instrument has 23 key items organized into six domains: scope and purpose (items 1 to 3); stakeholder involvement (items 4 to 7); rigour of development (items 8 to 14); clarity of presentation (items 15 to 18); applicability (items 19-21); and editorial independence (items 22 to 23). The tool is accompanied by a detailed User Guide that explains how to score the 23 items. Each guideline is assessed using a 4-point scale (ranging from 4 = "strongly agree" to $1=$ "strongly disagree") to rate each of the 23 items. These scores are then combined for each of the six domains and converted into standardized domain scores according to the following formula:

Standardized domain score $(\%)=$

obtained score - minimum possible score /

maximum possible score - minimum possible score $\times 100$

The six domain scores are independent and cannot be combined into a single score. Instead, appraisers can provide an overall assessment of the guideline according to the following categories:

1. Strongly recommended.

2. Recommended (with provisos or alterations).

3. Would not be recommended.

4. Unsure.

Two modifications were made to the AGREE tool to reduce the ambiguity and subjectivity associated with item scoring, and to enable the differentiation of good from poor quality guidelines.

1. A detailed set of instructions, or dictionary, based on the AGREE guidance was constructed using logical operators (AND, OR, NOT) to quantify what constitutes a score of $4,3,2$, or 1 for each of the 23 items.

2. Seven "essential" criteria were identified for categorizing guidelines as good, moderate, or poor quality (20).

a. Item 8: Systematic search conducted

b. Item 10: Methods used to formulate recommendations described

c. Item 12: Link between recommendations and evidence

d. Item 13: External review by experts

e. Item 15: Specific, unambiguous recommendations

f. Item 22: Editorially independent from funder

g. Item 23: Conflicts of interest reported

The scores from the two reviewers were combined into an average quality score (maximum possible of 28 [7×4]), which was then rated as follows:

Good: score of 22 to 28 ;

Average: score of 15 to 21 ;

Poor: score 0 to 14 .

ACKNOWLEDGEMENTS: The authors gratefully acknowledge Dr Ann Scott from the Institute of Health Economics (Edmonton, Alberta), who conducted the literature search and appraisal of the relevant studies. The authors also acknowledge the assistance of many CPS members and members of the NePSIG who responded to surveys and provided feedback and comments on earlier drafts of the recommendations.

FUNDING AND CONFLICTS OF INTEREST: The guideline was sponsored and funded by the CPS. The guideline is approved by the 
NePSIG, but the content and public ation of the guideline is solely the responsibility of the authors, as they had the final decision-making authority for the content and wording of the recommendations. The authors have no conflicts of interest with regard to the treatments reviewed in the recommendations.

\section{REFERENCES}

1. Dworkin RH, Backonja M, Rowbothan MC et al. Advances in neuropathic pain: Diagnosis, mechanisms, and treatment recommendations. Arch Neurol 2003;60:1524-34.

2. Finnerup NB, Otto M, McQuay HJ, et al. Algorithm for neuropathic pain treatment: An evidence based proposal. Pain 2005;118:289-305.

3. Attal N, Cruccu G, Haanpää M, et al. EFNS guidelines on pharmacological treatment of neuropathic pain. Eur J Neurol 2006;13:1153-69.

4. Moulin DE, Clark AJ, Gilron I, et al. Pharmacological management of chronic neuropathic pain - Consensus statement and guidelines from the Canadian Pain Society. Pain Res Manage 2007;12:13-21.

5. Manchikanti L, Boswell MV, Singh V, et al. Comprehensive evidence-based guidelines for interventional techniques in the management of chronic spinal pain. Pain Physician 2009; 12:699-802.

6. Chou R, Loeser JD, Owens DK, et al. Interventional therapies, surgery, and interdisciplinary rehabilitation for low back pain. Spine 2009;34:1066-77.

7. Netherlands Society of Rehabilitation Specialists and the Netherlands Society of Anaesthesiologists. Guideline: Complex regional pain syndrome type I. Alphen aan den Rijn, The Netherlands: Van Zuiden Communications B.V.; 2006. <www.cbo.nl/Downloads/341/rl_crps_eng_07.pdf> (Accessed November 3, 2011).

8. New Zealand Accident Compensation Corporation. Interventional pain management. New Zealand: New Zealand Accident Compensation Corporation, 2005. <www.acc.co.nz/for-providers/ clinical-best-practice/interventional-pain-management/ interventions/intervention-index/index.htm> (Accessed on November 3, 2011).

9. Boswell MV, Trescot AM, Datta S, et al. Interventional techniques: Evidence-based practice guidelines in the management of chronic spinal pain. Pain Physician 2007;10:7-111.

10. Dubinsky RM, Kabbani H, El-Chami Z, Boutwell C, Ali H. Practice parameter: Treatment of postherpetic neuralgia: An evidence-based report of the Quality Standards Subcommittee of the American Academy of Neurology. Neurology 2004;63:959-65.

11. Hunter Integrated Pain Service. Pain matters. Procedural intervention guideline. Newcastle, Australia: Hunter Integrated Pain Service, 2009. <www.hnehealth.nsw.gov.au/_data/assets/pdf_ file/0004/28165/Guideline_procedural_intervention.pdf> (Accessed February 16, 2009).

12. North American Spine Society. Diagnosis and treatment of degenerative lumbar spinal stenosis. Burr Ridge: USA: North American Spine Society, 2007. <www.spine.org/Documents/ NASSCG_Stenosis.pdf> (Accessed November 2, 2011).

13. Cruccu G, Aziz TZ, Garcia-Larrea L, Hansson P, et al. EFNS guidelines on neurostimulation therapy for neuropathic pain. Eur J Neurol 2007;14:952-70.

14. Institute of Health Economics Alberta Canada. The Health Technology Assessment (HTA). <www.ihe.ca/research/healthtechnology-assessment $>$ (Accessed November 11, 2011).

15. Cook DJ, Mulrow CD, Haynes RB. Systematic reviews: Synthesis of best evidence for clinical decisions. Ann Intern Med 1997;126:376-80.

16. Institute of Medicine. Clinical Practice Guidelines: Directions for a New Program. Field MJ, Lohr KN, eds. Washington, DC: National Academy Press, 1990. <www.nap.edu/catalog.php?record_id=1626> (Accessed November 1, 2011).

17. Wilson MC, Hayward RS, Tunis SR, Bass EB, Guyatt G. Users' guides to the medical literature. VIII. How to use clinical practice guidelines. B. What are the recommendations and will they help you in caring for your patients? The Evidence-Based Medicine Working Group. JAMA 1995;274:1630-2.

18. Veldhuijzen W, Ram P, van der WeijdenT, Wassink M, Van Der Vlenten C. Much variety and little evidence: A description of guidelines for doctor-patient communication. Med Education 2007;41:138-45.
19. United Nations Public Administration Network. List of Country Groupings and Sub-groupings for the Analytical Studies of the United Nations World Economic Survey and other UN Reports. United Nations Public Administration Network, 1995.

20. Institute of Health Economics (IHE). Nerve blocks for neuropathic pain: Summary of the literature. Edmonton (AB): IHE, 2009. $<$ www.canadianpainsociety.ca/pdf/nerve_blocks_final_report.pdf $>$ (Accessed November 7, 2011).

21. Institute of Health Economics (IHE). Spinal cord stimulation for neuropathic pain. Edmonton (AB): IHE, 2009. $<$ www.canadianpainsociety.ca/pdf/spinal_cord_stimulation_final_ report.pdf $>$ (Accessed November 8, 2011).

22. Institute of Health Economics (IHE). Epidural injection for neuropathic pain. Edmonton (AB): IHE; 2009.

$<$ www.canadianpainsociety.ca/pdf/epidural_injections_final_report. pdf $>$ (Accessed November 8, 2011).

23. Institute of Health Economics (IHE).Intravenous drug administration for neuropathic pain. Edmonton (AB): IHE, 2009. $<$ www.canadianpainsociety.ca/pdf/iv_infusions_final_report.pdf $>$ (Accessed November 13, 2011).

24. US Preventive Services Task Force. Methods and processes-grade definitions. <www.uspreventiveservicestaskforce.org/uspstf/grades. htm $>$ (Accessed Nov 10,2011)

25. Brainin M, Barnes M, Baron JC, et al. Guidance for the preparation of neurological management guidelines by EFNS scientific task forces - revised recommendations 2004. Eur J Neurol 2004;11:577-81.

26. Institute of Health Economics (IHE). Nerve blocks for neuropathic pain: Addendum to summary of the literature. Edmonton (AB): IHE, 2009. <www.canadianpainsociety.ca/pdf/nerve_blocks_final_ report_addendum.pdf $>$ (Accessed November 13, 2011).

27. Institute of Health Economics (IHE). Epidural injection for neuropathic pain - addendum to summary of the literature. Edmonton (AB): IHE, 2009. <www.canadianpainsociety.ca/pdf/ epidural_injections_final_report_addendum.pdf $>$ (Accessed November 12, 2011).

28. Institute of Health Economics (IHE). Intravenous drug administration for neuropathic pain - addendum to summary of the literature. Edmonton (AB): IHE, 2009. <www.canadianpainsociety. $\mathrm{ca} /$ pdf/iv_infusions_final_report_addendum_v2.pdf $>$ (Accessed November 13, 2011).

29. Kemler MA, de Vet HC, Barendse GA, van den Wildenberg FA, van Kleef M. Effect of spinal cord stimulation for chronic complex regional pain syndrome Type I: Five-year final follow-up of patients in a randomized controlled trial. J Neurosurg 2008;108:292-8.

30. Kumar K, Taylor RS, Jacques L, et al. Spinal cord stimulation versus conventional medical management for neuropathic pain: A multicentre randomised controlled trial in patients with failed back surgery syndrome. Pain 2007;132:179-88.

31. Ontario Ministry of Health and Long-Term Care. Spinal cord stimulation for neuropathic pain, 2005. <www.health.gov.on.ca/ english/providers/program/ mas/tech/techlist_mn.html> (Accessed September 10, 2008).

32. Gruccu G, Aziz TZ, Garcia-Larrea L, et al. EFNS guidelines on neurostimulation therapy for neuropathic pain. Eur J Neurol 2007;14:952-70.

33. Forouzanfar T, Koke AJ, Van KM, Weber WE. Treatment of complex regional pain syndrome type I. Eur J Pain 2002;6:105-22.

34. Hempenstall K, Nurmikko TJ, Johnson RW, A'Hern RP, Rice ASC. Analgesic therapy in postherpetic neuralgia: A quantitative systematic review. PLOS Medicine 2005;2:e164.

35. Kalso ET, Tramèr MR, McQuay HJ, Moore RA. Systemic localanaesthetic-type drugs in chronic pain: A systematic review. Eur J Pain 1998;2:3-14.

36. Kalso E, Edwards JE, Moore RA, McQuay HJ. Opioids in chronic non-cancer pain: Systematic review of efficacy and safety. Pain 2004;112:372-80.

37. Kingery WS. A critical review of controlled clinical trials for peripheral neuropathic pain and complex regional pain syndromes. Pain 1997;73:123-39.

38. Attal N, Rouaud J, Brasseur L, Chauvin M, Bouhassira D. Systemic lidocaine in pain due to peripheral nerve injury and predictors of response. Neurology 2004;62:218-25.

39. Brill S, Sedgwick PM, Hamann W, Di Vadi PP. Efficacy of intravenous magnesium in neuropathic pain. Br J Anaesth 2002;89:711-4. 
40. Eichenberger U, Neff F, Sveticic G, et al. Chronic phantom limb pain: The effects of calcitonin, ketamine, and their combination on pain and sensory thresholds. Anesth Anal 2008;106:1265-73.

41. Finnerup NB, Biering-Sorensen F, Johannesen IL, et al. Intravenous lidocaine relieves spinal cord injury pain: A randomized controlled trial. Anesthesiology 2005;102:1023-30.

42. Gottrup H, Bach FW, Juhl G, Jensen TS. Differential effect of ketamine and lidocaine on spontaneous and mechanical evoked pain in patients with nerve injury pain. Anesthesiology 2006;104:527-36.

43. Kvarnstrom A, Karlsten R, Quiding H, Emanuelsson BM, Gordh T. The effectiveness of intravenous ketamine and lidocaine on peripheral neuropathic pain. Acta Anaesthesiol Scand 2003;47:868-77.

44. Kvarnstrom A, Karlsten R, Quiding H, Gordh T. The analgesic effect of intravenous ketamine and lidocaine on pain after spinal cord injury. Acta Anaesthesiol Scand 2004:48:498-506.

45. Medrik-Goldberg T, Lifschitz D, Pud D, Adler R, Eisenberg E. Intravenous lidocaine, amantadine, and placebo in the treatment of sciatica: A double-blind, randomized, controlled study. Reg Anesth Pain Med 1999;24:534-40.

46. Robinson JN, Sandom J, Chapman PT. Efficacy of pamidronate in complex regional pain syndrome type I. Pain Med 2004;5:276-80.

47. Tremont-Lukats IW, Hutson PR, Backonja MM. A randomized, double-masked, placebo-controlled pilot trial of extended IV lidocaine infusion for relief of ongoing neuropathic pain. Clin J Pain 2006;22:266-71.

48. Viola V, Newnham HH, Simpson RW. Treatment of intractable painful diabetic neuropathy with intravenous lignocaine. J Diabetes Complications 2006;20:34-9.

49. Abdi S, Datta S, Trescot AM, et al. Epidural steroids in the management of chronic spinal pain: A systematic review. Pain Physician 2007;10:185-212.

50. Kumar V, Krone K, Mathieu A. Neuraxial and sympathetic blocks in herpes zoster and postherpetic neuralgia: An appraisal of current evidence. Reg Anesth Pain Med 2004;29:454-61.

51. Ackerman WE, Ahmad M. The efficacy of lumbar epidural steroid injections in patients with lumbar disc herniations. Anesth Analg 2007;104:1217-22.

52. Dincer U, Kiralp MZ, Cakar E, Yasar E, Dursan H. Caudal epidural injection versus non steroidal anti-inflammatory drugs in the treatment of low back pain accompanied with radicular pain. Joint, Bone, Spine: Revue du Rhumatisme 2007;74:467-71.

53. Owlia MB, Salimzadeh A, Alishiri G, Haghighi A. Comparison of two doses of corticosteroid in epidural steroid injection for lumbar radicular pain. Sing Med J 2007;48:241-5.

54. Pasqualucci A, Varrassi G, Braschi A, et al. Epidural local anesthetic plus corticosteroid for the treatment of cervical brachial radicular pain: Single injection versus continuous infusion. Clin J Pain 2007;23:551-7.

55. Zambello A. Epidural steroid injection vs paravertebral $\mathrm{O}_{2} \mathrm{O}_{3}$ infiltration for symptomatic herniated disc refractory to conventional treatment: A prospective randomized study. Rivista Italiana di Ossigeno-Ozonoterapia 2006;5:123-7.

56. Carragee EJ, Hurwitz EL, Cheng I, et al. Treatment of neck pain: Injections and surgical interventions: Results of the Bone and Joint Decade 2000-2010 Task Force on Neck Pain and Its Associated Disorders. Spine 2008;33(4 Suppl):S153-69.

57. DePalma MJ, Bhargava A, Slipman CW. A critical appraisal of the evidence for selective nerve root injection in the treatment of lumbosacral radiculopathy. Arch Phys Med Rehab 2005;86:1477-83.

58. Becker C, Heidersdorf S, Drewlo S, de Rodriguez SZ, Krämer J, Willburger RE. Efficacy of epidural perineural injections with autologous conditioned serum for lumbar radicular compression: An investigator-initiated, prospective, double-blind, referencecontrolled study. Spine 2007;32:1803-8.

59. Bonetti M, Fontana A, Cotticelli B, Volta GD, Guindani M, Leonardi M. Intraforaminal $\mathrm{O}_{2} \mathrm{O}_{3}$ versus periradicular steroidal infiltrations in lower back pain: Randomized controlled study. AJNR Am J Neuroradiol 2005;26:996-1000.

60. Livingstone JA, Atkins RM. Intravenous regional guanethidine blockade in the treatment of post-traumatic complex regional pain syndrome type 1 (algodystrophy) of the hand. J Bone Joint Surg Br 2002;84:380-6

61. Ng L, Chaudhary N, Sell P. The efficacy of corticosteroids in periradicular infiltration for chronic radicular pain: A randomized, double-blind, controlled trial. Spine 2005;30:857-62.
62. Nishiyama T. Comparison between neurotropin and mepivacaine for stellate ganglion injection. J Anesth 2006;20:240-2.

63. Taskaynatan MA, Ozgul A, Tan AK, Dincer K, Kalyon TA. Bier block with methylprednisolone and lidocaine in CRPS type I: A randomized, double-blinded, placebo-controlled study. Reg Anesth Pain Med 2004;29:408-12.

64. Ambrosio F, Finco G, Mattia C, et al. SIAARTI recommendations for chronic non-cancer pain. Minerva Anestesiologica 2006;72:859-80.

65. Workers' Compensation Board (WCB) Evidence Based Practice Group. Complex regional pain syndrome. Towards the development of diagnositic criteria and treatment guidelines. Vancouver, BC, Canada: Workers' Compensation Board of BC, 2004. <www.worksafebc.com/health_care_providers/Assets/PDF/CRPS.pdf> (Accessed November 3, 2011).

66. Jackson KC II. Pharmacotherapy for neuropathic pain. Pain Pract 2006;6:27-33.

67. Stafford MA, Peng P, Hill DA. Sciatica: A review of history, epidemiology, pathogenesis, and the role of epidural steroid injection in management. Br J Anaesth 2007;99:461-73.

68. Christo PJ, Hobelmann G, Maine DN. Post-herpetic neuralgia in older adults: Evidence-based approaches to clinical management. Drugs Aging 2007;24:1-19.

69. Henry JL, Lalloo C, Yashpal K. Central poststroke pain: An abstruse outcome. Pain Res Manag 2008;13:41-9.

70. Thomson S, Jacques L. Demographic characteristics of patients with severe neuropathic pain secondary to failed back surgery syndrome. Pain Pract 2009;9:206-15.

71. Ernst E. Complementary medicine for pain. <www.wellcome.ac.uk/ en/pain/microsite/medicine1.html> (Accessed November 3, 2011).

72. O'Connor AM, Bennett CL, Stacey D, et al. Decision aids for people facing health treatment or screening decisions. Cochrane Database Syst Rev 2009;(3):CD001431.

73. Légaré F, Ratté S, Stacey D, et al. Interventions for improving the adoption of shared decision making by healthcare professionals. Cochrane Database Syst Rev 2010;(5):CD006732.

74. Chou R, Atlas SJ, Loeser JD, Rosenquist RW. Guideline warfare over interventional therapies for low back pain: Can we raise the level of discourse? J Pain 2011;12:833-9.

75. Iversen T, Solberg T, Romner B, et al. Effect of caudal steroid or saline injection in chronic lumbar radiculopathy: A multicentre, blinded, ramdomised controlled trial. BMJ 2011;343:d5278 (doi:10.1136/bmj.d5278,2-15).

76. Manchikanti L, Singh V, Cash K, Pampati V, Damronk K, Boswell M. A randomized controlled double blind trial of fluoroscopic caudal epidural injections in the treatment of lumbar disc herniation and radiculitis. Spine 2011;36:1897-905.

77. Quraishi N. Transforaminal injection of corticosteroids for lumbar radiculopathy: Systematic review and meta-analysis. Eur Spine ] 2012;21:214-9.

78. Aggressive Research Intelligence Facility. ARIF Critical Appraisal Checklist. University of Birmingham 2008. <www.arif.bham.ac.uk/ critical-appraisal-checklist.shtml> (Accessed July 24, 2011).

79. Fishbain D, Cutler RB, Rosomoff HL, Rosomoff RS. What is the quality of the implemented meta-analytic procedures in chronic pain treatment meta-analyses? Clin J Pain 2000;16:73-85.

80. Greenhalgh T. How to read a paper: Papers that summarise other papers (systematic reviews and meta-analyses). BMJ 1997;315:672-5.

81. University of Alberta. Evidence Based Medicine Tool Kit. University of Alberta 2008. <www.ebm.med.ualberta.ca/> (Accessed July 24, 2011).

82. Shea BJ, Grimshaw JM, Wells GA, et al. Development of AMSTAR: A measurement tool to assess the methodological quality of systematic reviews. BMC Med Res Methodol 2007;7:10.

83. Oxman AD, Guyatt GH. Validation of an index of the quality of review articles. J Clin Epidemiol 1991;44:1271-8.

84. Van Tulder MW, Assendelft WJ, Koes BW, Bouter LM. Method guidelines for systematic reviews in the Cochrane Collaboration Back Review Group for spinal disorders. Spine 1997;22:2323-30.

85. Guzmán J, Esmail R, Karjalainen K, Malmivaara A, Irvin E, Bombardier C. Multidisciplinary bio-psycho-social rehabilitation for chronic low back pain. Cochrane Database Syst Rev2006;(2):CD000963. DOI:10.1002/14651858.CD000963.pub2.

86. Niemisto L, Kalso E, Malmivaara A, Seitsalo S, Hurri H. Radiofrequency denervation for neck and back pain. Cochrane 
Database Syst Rev 2003(1):CD004058. DOI: 10.1002/14651858. CD004058.

87. Ostelo RW, van Tulder MW, Vlaeyen JW, Linton SJ, Morley SJ, Assendelft WJ. Behavioural treatment for chronic low back pain. Cochrane Database Syst Rev 2005;(1):CD002014. DOI: 10.1002/14651858.CD002014.pub2.

88. Jadad AR, Moore RA, Carroll D, et al. Assessing the quality of reports of randomized clinical trials: Is blinding necessary? Control Clin Trials 1996;17:1-12.

89. Verhagen AP, de Vet HC, de Bie RA, et al. The Delphi list: A criteria list for quality assessment of randomized clinical trials for conducting systematic reviews developed by Delphi consensus. J Clin Epidemiol 1998;51:1235-41.

90. Downs SH, Black N. The feasibility of creating a checklist for the assessment of the methodological quality both of randomised and non-randomised studies of health care interventions.

J Epidemiol Community Health 1998;52:377-84.

91. The AGREE Collaboration. Appraisal of Guidelines for Research and Evaluation (AGREE) Instrument. The AGREE Collaboration 2001. <www.agreecollaboration.org/pdf/agreeinstrumentfinal.pdf> (Accessed July 24, 2011). 


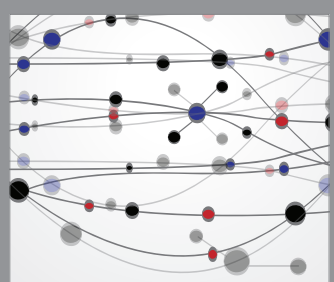

The Scientific World Journal
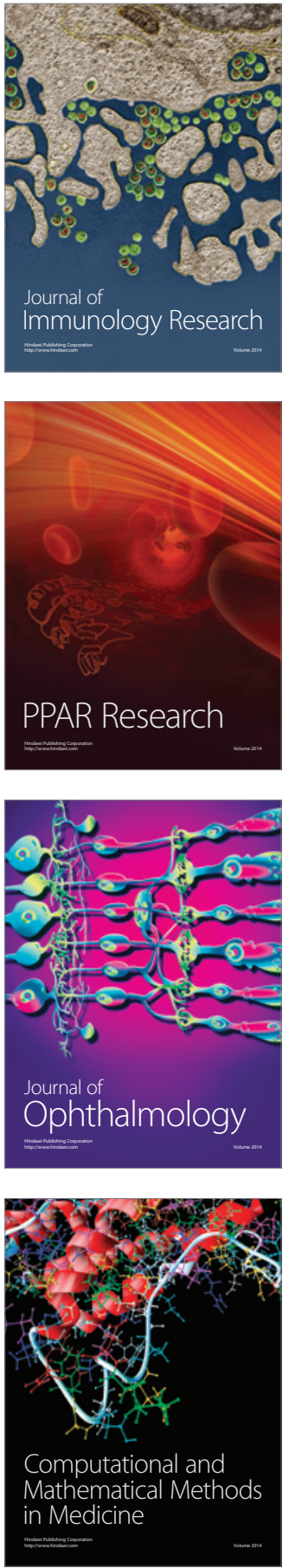

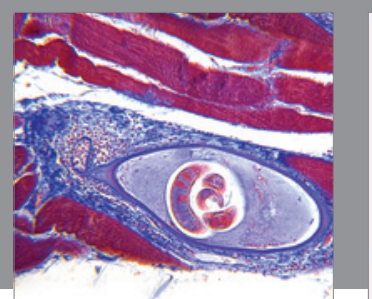

Gastroenterology Research and Practice

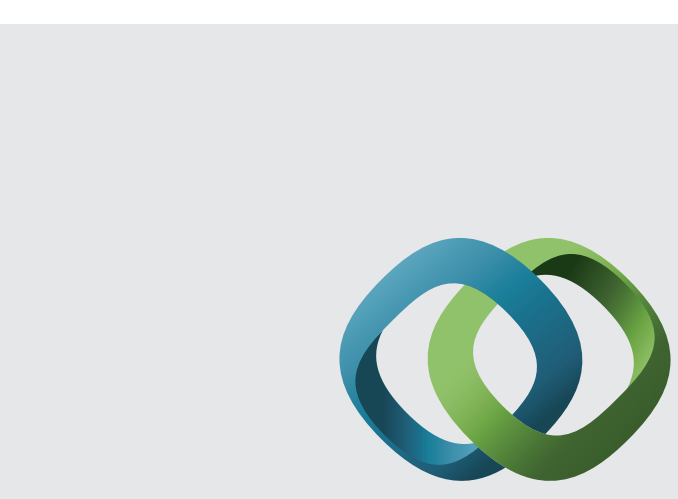

\section{Hindawi}

Submit your manuscripts at

http://www.hindawi.com
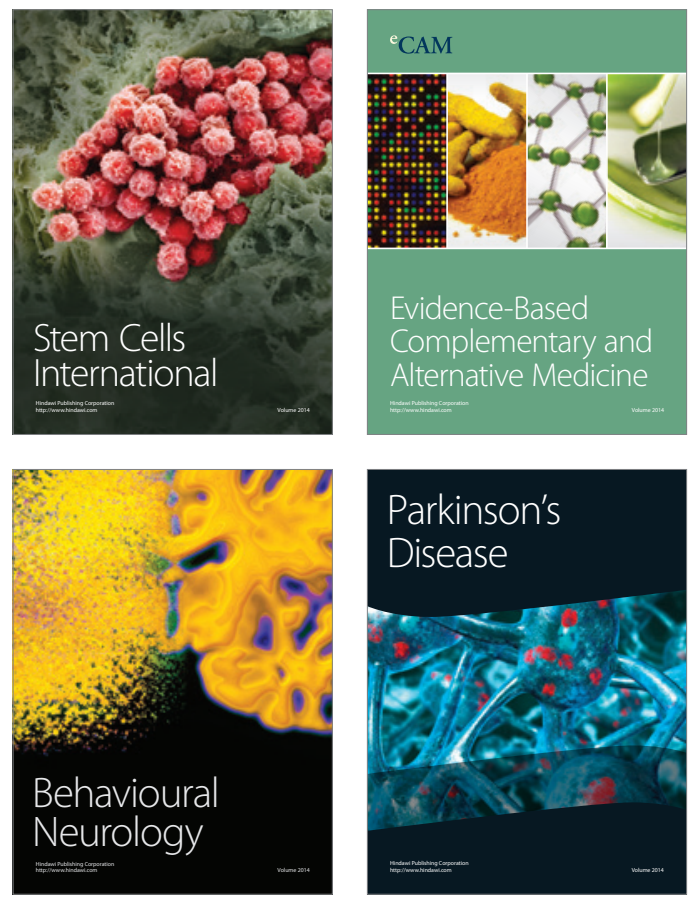
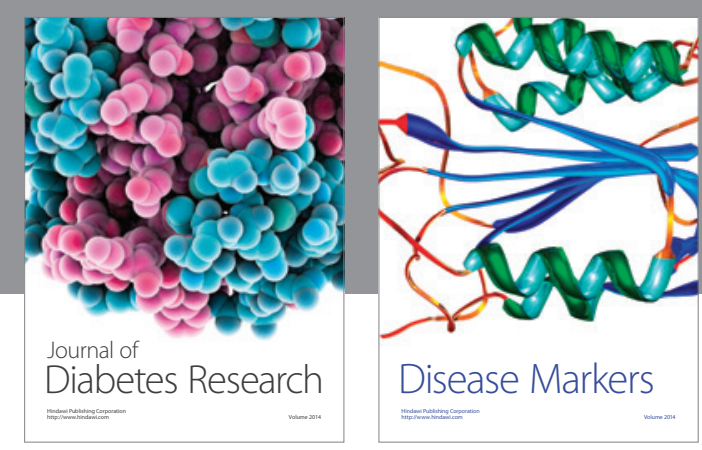

Disease Markers
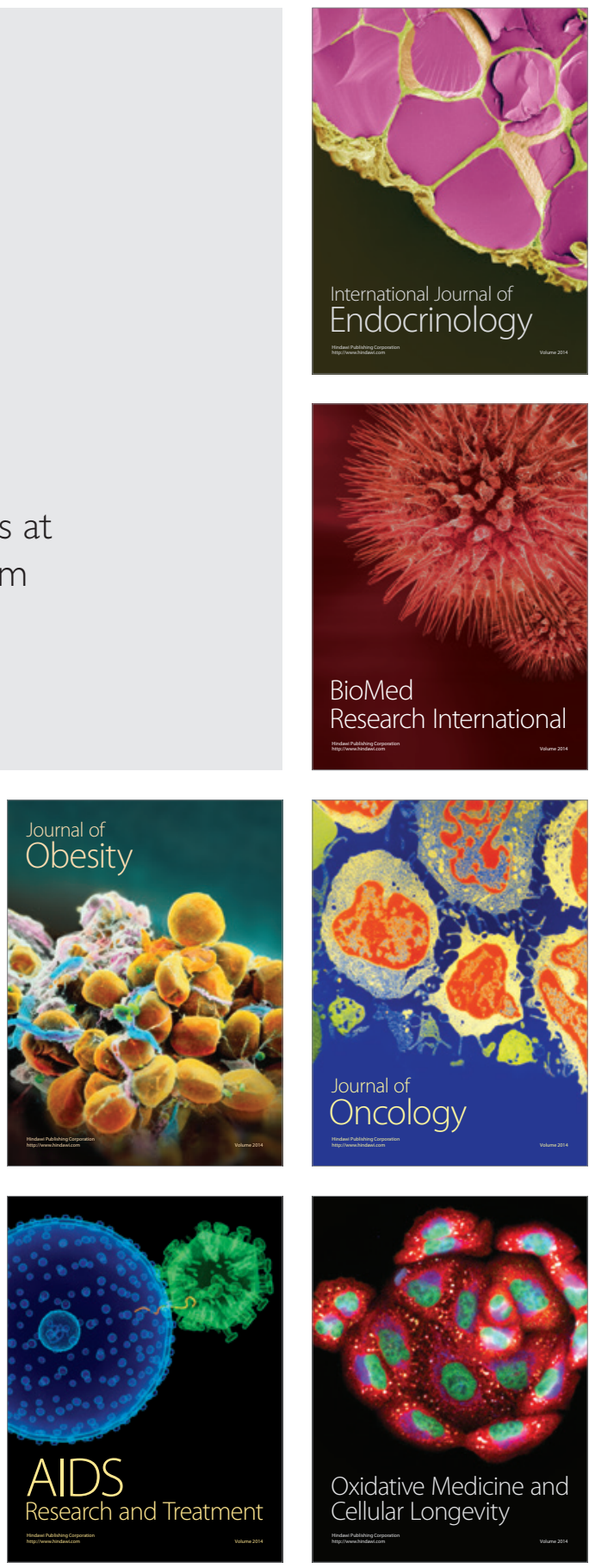